\section{Condições de trabalho e saúde dos professores da rede particular de ensino de Vitória da Conquista, Bahia, Brasil}

\author{
Labor and health conditions of private school \\ teachers in Vitória da Conquista, Bahia, Brazil
}

\author{
1 Faculdade de Medicina, \\ Universidade Federal \\ da Bahia,Salvador, Brasil. \\ 2 Núcleo de Epidemiologia, \\ Departamento de Saúde, \\ Universidade Estadual \\ de Feira de Santana, \\ Feira de Santana, Brasil. \\ Correspondência \\ Fernando M. Carvalho, \\ Departamento de Medicina \\ Preventiva, Universidade \\ Federal da Bahia. \\ Rua Cláudio Manoel \\ da Costa 74, apto. 1401, \\ Salvador, $B A$ \\ 40110-180, Brasil. \\ fmc@ufba.br
}

\begin{abstract}
The scientific literature on teachers' health is scarce, recent, and focuses predominantly on stress and burnout. This study describes the labor conditions of private school teachers in Vitória da Conquista, Bahia State, Brazil. Information on 250 teachers from the ten largest schools in the municipality was collected through a self-applied questionnaire. The most relevant characteristics of teachers' work, evaluated by the Job Content Questionnaire were: speed of work, creativity at work, and relations with colleagues. The most frequent complaints related to posture, mental strain, and voice problems. Prevalence of minor psychological disorders according to the Self Reporting Questionnaire-20 was 41.5\%, strongly associated with long periods of intense concentration on the same job and excessive work. Results suggest an association between the prevalence of minor psychological disorders and certain characteristics of teaching work, emphasizing teachers' exposure to stress.
\end{abstract}

Working Conditions; Occupational Health; Faculty

\author{
Núria Serre Delcor 1 \\ Tania M. Araújo 2 \\ Eduardo J. F. B. Reis 1 \\ Lauro A. Porto 1 \\ Fernando M. Carvalho 1 \\ Manuela Oliveira e Silva 1 \\ Leonardo Barbalho 1 \\ Jonathan Moura de Andrade 1
}

\section{Introdução}

O trabalho humano possui um duplo caráter: por um lado é fonte de realização, satisfação, prazer, estruturando e conformando o processo de identidade dos sujeitos; por outro, pode também se transformar em elemento patogênico, tornando-se nocivo à saúde 1 . No ambiente de trabalho, os processos de desgaste do corpo são determinados em boa parte pelo tipo de trabalho e pela forma como esse está organizado.

No Brasil, a literatura científica sobre as condições de trabalho e saúde dos professores é ainda restrita. Entretanto, a partir da década de 90, observou-se um aumento no número de estudos conduzidos neste grupo ocupacional. Estes estudos exploram especialmente os efeitos do trabalho sobre a saúde mental, como estresse e a Síndrome de Burnout. Esta síndrome afeta especialmente trabalhadores com muito contato social, como nos setores de Educação e Saúde 2.

As investigações de Codo 3 sobre a saúde mental dos professores de 1o e 2 o graus em todo o país, abrangendo 1.440 escolas e $30 \mathrm{mil}$ professores, revelaram que $26 \%$ da amostra estudada apresentavam exaustão emocional. Essa proporção variou de $17 \%$ em Minas Gerais e Ceará a 39\% no Rio Grande do Sul. A desvalorização profissional, baixa auto-estima e ausência de resultados percebidos no trabalho de- 
senvolvido foram fatores importantes para o quadro encontrado.

Araújo et al. 4 e Silvany et al. 5 realizaram amplos estudos sobre as condições de saúde e trabalho de 573 professores da rede particular de ensino em Salvador, Bahia, em 1996. Problemas de saúde nos 15 dias anteriores à entrevista foram referidos por $32,5 \%$ dos professores. As queixas de saúde mais freqüentes foram dores nas costas e pernas e, no âmbito psicoemocional, cansaço mental e nervosismo. Ter calos nas cordas vocais foi referido por $12 \%$ dos professores. A prevalência de distúrbios psíquicos menores foi de $20 \%$, associada a trabalho repetitivo, insatisfação no desempenho das atividades, ambiente intranqüilo e estressante, desgaste na relação professor-aluno, falta de autonomia no planejamento das atividades, ritmo acelerado de trabalho e à pressão da direção.

A avaliação das condições de saúde e trabalho de professores da rede particular de ensino é relevante porque: (1) há um número expressivo e crescente de profissionais desta categoria no Brasil 6; (2) a maioria dos estudos realizados avaliaram saúde e trabalho de professores de escolas públicas 5 , os quais estão submetidos a processo e organização do trabalho distintos dos existentes nas escolas privadas.

O objetivo deste estudo foi descrever as condições de trabalho e saúde de professores da rede particular de ensino de Vitória da Conquista, Bahia.

\section{Metodologia}

Realizou-se um estudo epidemiológico de corte transversal. Na cidade de Vitória da Conquista, em 2001, existiam 35 escolas da rede particular de ensino, cadastradas pelo Sindicato dos Professores da Rede Privada de Ensino da Bahia (SINPRO/BA), com 600 a 700 professores. Foram incluídos todos os professores, de ensino pré-escolar até ensino médio, das dez maiores escolas da rede particular de ensino da cidade. Foram excluídos do estudo professores de educação física, informática e línguas estrangeiras. Na coleta de dados foi utilizado um formulário auto-aplicado com cinco blocos de questões.

O primeiro bloco continha informações sobre características demográficas e econômicas, características ocupacionais e atividades domésticas.

O segundo bloco avaliou esforços físicos no trabalho, em sete questões medidas em uma escala de 0 a 3 ( 0 = raramente; $1=$ pouco freqüente; 2 = freqüente e 3 = muito freqüente), situações de risco no trabalho em oito questões medidas em escala de 0 a $3(0=$ risco inexistente; $1=$ baixo risco; $2=$ médio risco e $3=$ alto risco) e conteúdo do trabalho, medido baseando-se no Job Content Questionnaire (JCQ) modificado 7,8. A versão do JCQ em português inclui 41 questões: 17 a respeito do controle sobre o trabalho ( 6 sobre habilidades e 11 sobre poder de decisão), 13 perguntas sobre demandas psicológicas (8) e físicas (5), e 11 perguntas sobre suporte social. Trinta e oito questões foram medidas em uma escala de 1 a 4 ( $1=$ discordo fortemente; 2 = discordo; 3 = concordo $\mathrm{e}$ 4 = concordo fortemente); as outras três perguntavam sobre o número de funcionários que coordena o professor, o número de pessoas no grupo de trabalho e sobre ser ou não membro do sindicato. O JCQ tem sido usado em vários países, especialmente nos Estados Unidos, Canadá, Europa, Japão e Coréia do Sul. Estudos de validação do JCQ indicam bom desempenho deste instrumento 9,10. No Brasil, ainda não foi conduzido estudo para sua validação. Contudo, resultados obtidos em estudos brasileiros que utilizaram o JCQ têm mostrado consistência com resultados obtidos em outros países 11 , revelando que o instrumento apresenta bom desempenho na identificação e classificação de diferentes situações de trabalho.

O terceiro bloco investigou a saúde física. Avaliaram-se trinta queixas de saúde, classificadas em uma escala de 0 a 4 ( 0 = não sente; 1 = raramente; 2 = pouco freqüente; 3 = freqüente e $4=$ muito freqüente). Também incluiu-se questões relacionadas com a voz, em escala de resposta Sim/Não e sobre o hábito de fumar.

O quarto bloco avaliou a saúde mental e nível de suspeição de consumo abusivo de álcool. A saúde mental foi avaliada por meio de um instrumento de detecção de distúrbios psíquicos menores, o Self Reporting Questionnaire-20 (SRQ-20), desenvolvido por Harding et al. 12. Foram classificados como suspeitos de apresentar distúrbios psíquicos menores (DPM), os professores que responderam positivamente a sete ou mais questões dentre as vinte propostas pelo teste. Estudos de validação do SRQ-20 foram realizados no Brasil por Mari 13 e Fernandes \& Almeida Filho 14. Indivíduos com duas ou mais respostas positivas as quatro questões tipo Sim/Não do teste C.A.G.E. foram classificados como suspeitos de alcoolismo 15.

O quinto bloco incluiu questões sobre utilização de Serviço de Medicina e Segurança do Trabalho nas escolas, diagnósticos médicos desde o início do trabalho como professor, acidentes do trabalho, problemas de saúde nos últimos 15 dias, atividade física e lazer. 
Em função das questões abordadas pelos instrumentos de pesquisa e objetivando diminuir ao máximo possíveis resistências, manteve-se o anonimato do formulário, não sendo solicitado ao professor que se identificasse. A coleta de dados foi realizada por estudantes de medicina devidamente treinados, no período de setembro a novembro de 2001. Para garantir níveis mais elevados de padronização, além do treinamento foi utilizado um manual de instruções básicas para orientar os procedimentos durante as entrevistas. Foram efetuadas visitas prévias para contatos com a direção das escolas, a fim de obter permissão para a realização da pesquisa. Obtida a listagem de professores e o consentimento assinado de cada um deles, entrevistas foram realizadas em cada escola, coletando-se os questionários dentro de envelopes fechados para garantir o anonimato.

Com o programa SPSS foram calculadas freqüências e medidas de tendência central para a descrição das variáveis. Para a análise bivariada, as variáveis do JCQ foram dicotomizadas. O teste do qui-quadrado foi utilizado para identificar prováveis associações entre variáveis, tomando como estatisticamente significante o nível de probabilidade de 5\%. Razões de prevalência e respectivos intervalos de confiança 95\% foram calculados.

\section{Resultados}

Dos 309 professores das dez escolas selecionadas, $250(80,9 \%)$ responderam o questionário. Dos 59 professores que não entraram no estudo, um estava com licença por maternidade, um encontrava-se no hospital, três recusaramse a participar verbalmente e 54 não devolveram o questionário.
Os professores de Vitória da Conquista tinham média de idade de $34,5 \pm 7,5$ anos, $82,8 \%$ eram mulheres, $65,1 \%$ casadas e $72,1 \%$ com nível de escolaridade superior (em curso ou completo). Trabalhavam em outra escola 59,3\% e em mais de duas escolas $9,2 \%$. Desenvolviam outras atividades remuneradas além da docência $19,1 \%$. As características do trabalho destes professores são apresentadas na Tabela 1 .

A renda mensal média foi de $\mathrm{R} \$ 886,00$, correspondente na época da coleta a US\$345. Vinte e três por cento recebiam menos de $\mathrm{R} \$$ 400,$00 ; 33 \%$ de $\mathrm{R} \$ 401,00$ a $\mathrm{R} \$ 800,00 ; 23 \%$ de $\mathrm{R} \$ 801,00$ a R\$ $1.100,00$ e $21 \%$ de $\mathrm{R} \$ 1.101,00 \mathrm{ou}$ mais. Entre aqueles que realizavam atividades domésticas, $16 \%$ não recebiam ajuda ( $16 \%$ nas mulheres e $20 \%$ nos homens), geralmente de uma empregada doméstica.

Esforços físicos realizados no trabalho ou associados a ele, apontados como "freqüentes" ou "muito freqüentes", foram: permanecer em pé $(96,7 \%)$ e correção de trabalhos escolares $(94,1 \%)$. As situações de risco na escola mais apontadas como de "médio" ou "alto risco", foram risco de queda e torções (24\%) e acidentes de trânsito (17,9\%). Mais da metade dos professores responderam que "concordaram" ou "concordaram fortemente" em algumas questões do JCQ que identificavam aspectos negativos para o bom desenvolvimento do seu trabalho: ritmo acelerado de trabalho $(67,9 \%)$; posição inadequada e incômoda do corpo $(65,4 \%)$; atividade física rápida e contínua $(63,8 \%)$; ritmo frenético de trabalho $(54,9 \%)$; posições da cabeça e braços inadequadas e incômodas $(53,4 \%)$ e longos períodos de intensa concentração em uma mesma tarefa $(51,9 \%)$. Naquelas questões do JCQ consideradas como positivas para o desenvolvimento do trabalho, mais de $90 \%$ dos professores "concordaram" ou "concordaram fortemente" em: necessidade de ser

Características do trabalho de professores da rede particular de ensino de Vitória da Conquista, Bahia, Brasil, 2001.

\begin{tabular}{|c|c|c|c|}
\hline Características do trabalho & $\mathbf{N}$ & Média & Desvio-padrão \\
\hline Tempo de trabalho como professor (em anos) & 234 & 11,4 & 6,9 \\
\hline Número total de turmas & 248 & 3,9 & 3,0 \\
\hline Número total de alunos por turma & 244 & 30,1 & 9,1 \\
\hline Carga horária total semanal na escola & 221 & 19,4 & 8,4 \\
\hline Carga horária semanal em sala de aula & 230 & 17,0 & 7,4 \\
\hline $\begin{array}{l}\text { Carga horária semanal em todas as escolas } \\
\text { (sala de aula e outras atividades) }\end{array}$ & 239 & 34,3 & 16,9 \\
\hline
\end{tabular}

$\mathrm{N}$ = número de professores incluídos na análise. 
criativo (99,2\%); necessidade de um alto nível de habilidade (96,0\%); possibilidade de aprender novas coisas $(94,7 \%)$; opinaram que os colegas são competentes em fazer suas atividades $(91,2 \%)$; opinaram que as pessoas no trabalho eram amigáveis $(90,7 \%)$ e possibilidade de dar opinião sobre o que acontece no seu trabalho $(90,6 \%)$.

Os professores referiram, em média, 7,2 \pm 5,7 queixas de saúde, dentre uma lista de trinta queixas, todas rotuladas como sendo "freqüentes" ou "muito freqüentes". Destacaram-se as queixas de saúde relacionadas à postura: dor nos braços/ombro $(52,1 \%)$, dor nas costas $(51,4 \%)$ e dor nas pernas/formigamento (47,5\%); problemas psicossomáticos ou relacionados à saúde mental: cansaço mental $(59,2 \%)$ e problemas relacionados ao uso intensivo da voz: dor na garganta $(45,7 \%)$ (Tabela 2$)$.

Encontrou-se que $92,6 \%$ dos professores referiram uso intensivo da voz, $62,3 \%$ cansavamse para falar e $57 \%$ faziam força para serem ouvidos. Rouquidão nos últimos seis meses foi referida por $59,2 \%$ dos professores. Nesta população, 4,2\% eram fumantes atuais e 11,4\% exfumantes. O consumo de bebida alcóolica foi referido por $22,1 \%$ dos professores. O teste C.A.G.E. classificou 1,3\% dos professores como suspeitos de dependência do álcool.

Dos 250 professores, 94,8\% responderam a todas as perguntas do SRQ-20. A prevalência de distúrbios psíquicos menores estimada pelo SRQ-20 foi de $41,5 \%$, variando de $17,6 \%$ a $66,7 \%$ dentre as escolas estudadas. A prevalência de DPM estava estatisticamente associada $(p=0,05$, respostas "concordaram" ou "concordaram fortemente”) com características do conteúdo do trabalho: trabalho repetitivo $(\mathrm{RP}=1,64)$, intensa concentração em uma mesma tarefa por um longo período $(\mathrm{RP}=1,76)$, volume excessivo de trabalho $(\mathrm{RP}=1,65)$, ritmo acelerado de trabalho ( $R P=1,49)$, interrupção das tarefas antes de serem concluídas ( $\mathrm{RP}=1,38)$, tempo para realização das tarefas insuficiente $(R P=1,36)$, ausência de preocupação do coordenador pelo bem-estar da sua equipe ( $R P=1,50)$, inexistência de processos democráticos de tomada de decisões do grupo de trabalho $(R P=1,46)$, falta de interesse dos colegas de trabalho pelo que acontece com você $(R P=1,43)$ e exposição a hostilidades e conflitos com os colegas de trabalho $(\mathrm{RP}=1,39)$ (Tabela 3$)$.

Apenas 28\% dos professores realizavam os exames médicos periódicos previstos na legislação. De 233 indivíduos que responderam sobre diagnósticos médicos recebidos desde que começaram a trabalhar como professor, $73,4 \%$ referiram no mínimo um diagnóstico e $26,6 \%$ referiram não ter diagnósticos de qualquer problema de saúde. Os diagnósticos médicos mais freqüentemente referidos foram: varizes em membros inferiores $(36,1 \%)$, gastrite ou esofagite (24\%), infeções do trato urinário (18\%), sinusite crônica $(17,6 \%)$, LER $(17,6 \%)$ e calos nas cordas vocais $(13,3 \%)$ (Tabela 4$)$.

A associação entre a queixa de dor/formigamento nas pernas e o fato de o professor permanecer de pé foi fraca ( $R P=0,99$; IC95\%: 0,44$2,22)$ e não sofreu confundimento importante devido à presença de varizes $\left(\mathrm{RP}_{\text {Mantel-Haenszel }}=\right.$ 1,05; IC95\%: 0,48-2,29).

Problemas de saúde nos 15 dias anteriores à entrevista foram referidos por $39,4 \%$ dos professores. Acidentes de trabalho foram referidos por $7,1 \%$. Atividade física fora do trabalho foi referida por $38,9 \%$ dos professores. Cinqüenta e três por cento dos professores disseram que dedicavam algum tempo semanal ao lazer durante a semana.

\section{Discussão}

Os professores estudados da rede particular de ensino de Vitória da Conquista, representam uma população jovem, principalmente do sexo feminino, casadas e com nível de escolaridade superior. Estes dados sócio-demográficos e de escolaridade são similares aos relatados por Silvany et al. 5 em professores da rede privada de Salvador, Bahia.

A predominância da mulher na profissão de educar também aparece em outras pesquisas sobre a saúde e trabalho dos professores de ensino básico, variando de 75 a 85,6\% 3,5,6,16,17. Com a expansão do setor educacional no Brasil, a partir da segunda metade do século XX, foi preciso a incorporação de muitos trabalhadores para o ensino. A docência, assim como a enfermagem, foi considerada na época, atividade própria das mulheres por envolver "o cuidado dos outros”. As mulheres foram chamadas para ocupar os cargos de educadoras, considerando-se o trabalho na escola como uma continuação das tarefas exigidas no âmbito doméstico, aparecendo a imagem da "mãe educadora". A crise econômica, a crise de emprego, a luta das mulheres pelos seus direitos e as mudanças na família nuclear favoreceram a entrada da mulher no mundo do trabalho. Os baixos salários dos educadores também fazem com que as mulheres ocupem esses trabalhos, para complementar a renda familiar 3. Porém, a proporção de professores do sexo masculino vem aumentando no ensino médio em relação ao pré-escolar. No estudo de Codo ${ }^{3}$, os homens 
Freqüência de queixas de saúde referidas como "freqüentes" ou "muito freqüentes" pelos professores da rede particular de Vitória da Conquista, Bahia, Brasil, 2001.

\begin{tabular}{|c|c|c|c|}
\hline Queixas de saúde referidas & $\mathrm{n}$ & $\begin{array}{l}\text { Freqüência } \\
\text { simples }\end{array}$ & $\begin{array}{l}\text { Freqüência } \\
\text { relativa (\%) }\end{array}$ \\
\hline \multicolumn{4}{|c|}{ Problemas psicossomáticos ou relacionados à saúde mental } \\
\hline Cansaço mental & 240 & 142 & 59,2 \\
\hline Esquecimento & 241 & 89 & 36,9 \\
\hline Nervosismo & 243 & 80 & 32,9 \\
\hline Insônia & 245 & 46 & 18,8 \\
\hline Azia/queimação & 240 & 46 & 19,2 \\
\hline \multicolumn{4}{|c|}{ Problemas relacionados à postura corporal } \\
\hline Dor nos braços/ombro & 242 & 126 & 52,1 \\
\hline Dor nas costas & 243 & 125 & 51,4 \\
\hline Dor/formigamento nas pernas & 242 & 115 & 47,5 \\
\hline Dor na coluna & 241 & 104 & 43,2 \\
\hline Inchaço nas pernas & 240 & 26 & 10,8 \\
\hline \multicolumn{4}{|c|}{ Problemas relacionados ao uso intensivo da voz } \\
\hline Dor na garganta & 245 & 112 & 45,7 \\
\hline Perda temporária de voz & 240 & 54 & 22,5 \\
\hline \multicolumn{4}{|c|}{ Problemas relacionados à poeira e pó de giz } \\
\hline Entupimento nasal & 240 & 67 & 27,9 \\
\hline Rinite & 237 & 66 & 27,8 \\
\hline Tosse & 242 & 52 & 21,5 \\
\hline Irritação nos olhos & 242 & 43 & 17,8 \\
\hline Coriza & 240 & 41 & 17,1 \\
\hline Problemas de pele & 242 & 35 & 14,5 \\
\hline \multicolumn{4}{|l|}{ Outros problemas } \\
\hline Sonolência & 243 & 74 & 30,5 \\
\hline Queda dos cabelos & 241 & 66 & 27,4 \\
\hline Redução da visão & 240 & 52 & 21,7 \\
\hline Problemas digestivos & 238 & 46 & 19,3 \\
\hline Tontura & 244 & 38 & 15,6 \\
\hline Fraqueza & 240 & 36 & 15,0 \\
\hline Zumbido & 240 & 35 & 14,6 \\
\hline Falta de ar & 240 & 24 & 10,0 \\
\hline Palpitações & 238 & 21 & 8,8 \\
\hline Não ouve bem & 240 & 16 & 6,7 \\
\hline Ardor ao urinar & 240 & 12 & 5,0 \\
\hline Dor no peito & 240 & 11 & 4,6 \\
\hline
\end{tabular}

$\mathrm{N}$ = número de professores incluídos na análise. 
Razões de prevalência (RP) e respectivos intervalos de confiança de 95\% (IC 95\%) para a associação entre distúrbios psíquicos menores e questões do Job Content Questionnaire (JCQ), nos professores a rede particular de ensino de Vitória da Conquista, Bahia, Brasil, 2001.

\begin{tabular}{|c|c|c|}
\hline Questões do JCQ & $\mathbf{n}$ & RP (IC95\%) \\
\hline \multicolumn{3}{|l|}{ Controle } \\
\hline O seu trabalho é repetitivo? & 245 & $1,64(1,23-2,20)$ \\
\hline \multicolumn{3}{|l|}{ Demanda psicológica } \\
\hline Seu trabalho exige longos períodos de intensa concentração em uma mesma tarefa? & 236 & $1,76(1,27-2,44)$ \\
\hline Você é solicitado a realizar um volume excessivo de trabalho? & 246 & $1,65(1,23-2,20)$ \\
\hline Seu trabalho é realizado sob ritmo acelerado? & 245 & $1,49(1,03-2,13)$ \\
\hline $\begin{array}{l}\text { Suas tarefas muitas vezes são interrompidas antes que você possa concluí-las, } \\
\text { adiando para mais tarde a sua conclusão? }\end{array}$ & 227 & $1,38(1,02-1,87)$ \\
\hline O tempo para realização das suas tarefas não é suficiente para concluí-las? & 244 & $1,36(1,02-1,82)$ \\
\hline \multicolumn{3}{|l|}{ Suporte social } \\
\hline Falta de preocupação do coordenador com o bem-estar da sua equipe de trabalho? & 231 & $1,50(1,13-2,00)$ \\
\hline Seu grupo de trabalho ou unidade não toma decisões democraticamente? & 232 & $1,46(1,08-1,96)$ \\
\hline Falta de interesses das pessoas por você com quem você trabalha? & 230 & $1,43(1,06-1,93)$ \\
\hline Exposição a hostilidades e conflitos com as pessoas com quem você trabalha? & 235 & $1,39(1,02-1,89)$ \\
\hline
\end{tabular}

$\mathrm{N}$ = número de professores incluídos na análise.

representavam $2,6 \%$ da pré-escola a quarta série e $39,2 \%$, no segundo grau. No presente estudo, 2,0\% dos professores no nível pré-escolar eram homens e 47,5\%, no nível médio. Em outros estudos sobre condições de saúde e trabalho docente no nível superior, a proporção de professores do sexo feminino variou de $34,5 \%$ a $61,5 \% 18,19,20$.

O fato de a mulher participar mais nos níveis iniciais de ensino, pode responder a uma maior demanda de um educador com o papel de "mãe" nos primeiros anos de escolaridade. Todos os professores homens de nosso estudo ( $n=42$ ) possuíam nível de escolaridade superior, o que favorece a que eles ensinem classes de níveis mais elevados. Em nosso estudo, todos os educadores de ensino médio possuíam nível de escolaridade superior e só três professores do ensino fundamental II não o possuíam.

Destacou-se a alta porcentagem de professores com nível de escolaridade superior em Vitória da Conquista, similar à de $71,9 \%$, encontrada em Salvador 5. Dados do Ministério do Trabalho 21 apontam apenas $22,3 \%$ dos professores da rede particular de ensino do Estado da Bahia com nível de escolaridade superior. A Lei de Diretrizes e Bases da Educação (aprovada em dezembro de 1996) que passou a exigir escolaridade superior para todos os níveis de ensino, poderia ser a responsável por este aumento no nível de qualificação dos docentes.

Em Vitória da Conquista, 26,2\% dos professores trabalhavam simultaneamente em outras escolas privadas e $28,4 \%$ trabalhavam em outras escolas da rede estadual ou municipal. Em Salvador, as porcentagens correspondentes foram $43,1 \%$ e $20,2 \%$, respectivamente 5 . Estas diferenças podem indicar uma menor oferta de trabalho em outras escolas em Vitória da Conquista, ou a necessidade de trabalhar em várias escolas para aumentar a renda familiar, em Salvador. Mesmo assim, muitos professores de Vitória da Conquista trabalhavam em outras escolas ou em outra atividade remunerada, indicando a necessidade de complementar uma renda familiar insuficiente, com outros trabalhos, inclusive fora da área da docência.

A carga horária média semanal de trabalho em todas as escolas (em sala de aula e atividades extraclasse) foi elevada. A essa carga horária ainda devem ser somadas as horas para a preparação de aulas, os deslocamentos de uma escola para outra e as atividades domésticas. Segundo Gomes 22, as atividades domésticas ocupam de 2 a 3 horas por dia do tempo do professor. Esta situação agrava-se para aqueles professores que não recebiam qualquer tipo de ajuda em casa. Com toda essa carga de trabalho, $56,0 \%$ dos professores tinham renda men- 
sal inferior a quatro salários mínimos (R $\$ 720,00$ ou US\$270). Segundo Esteve 23, a sociedade atual estabelece o status social com base no nível salarial. Os baixos salários dos professores estudados podem ser um forte fator na crise de identidade e na insatisfação da categoria, podendo afetar a saúde mental destes trabalhadores.

Os esforços físicos realizados no trabalho foram freqüentemente apontados pelos entrevistados, destacando-se permanecer em pé, queixa também freqüente nos estudos de Paranhos 20 e de Araújo et al. 4, e correção de trabalhos escolares. Na presente base de dados, não foi demonstrada associação entre dor/formigamento nas pernas e a freqüente permanência em pé, mesmo entre os professores que referiram padecer de varizes. Explicações para este fato inusitado devem ser buscadas após a consideração de outros possíveis confundidores que não foram aqui analisados.

As situações de risco no trabalho foram pouco apontadas. De fato, a profissão de educador, pela sua natureza, não tem por que comportar riscos físicos relevantes.

Destacou-se a alta porcentagem de professores que identificaram características possivelmente associadas aos principais problemas de saúde apontados pela categoria. Manter uma posição inadequada e incômoda do corpo e precisar de esforço físico para desenvolver o trabalho poderiam estar associados às queixas relacionadas à postura corporal.

Os professores valorizaram predominantemente aqueles aspectos do trabalho relacionados ao controle e ao suporte social. Os aspetos negativos especialmente apontados foram os relacionados com a demanda psicológica e física no trabalho. Esses dados são similares a outros estudos com professores. Ritmo acelerado de trabalho foi referido por $67,9 \%$ dos professores de Vitória da Conquista e por 60,6\% dos professores investigados em Salvador, Bahia 5. Em Navarra, Espanha, uma pesquisa sobre saúde e trabalho dos professores encontrou que as principais queixas foram atenção elevada, ritmo de trabalho elevado e volume de trabalho excessivo, três aspectos que medem a demanda psicológica no trabalho 24 . Professores da Universidade Estadual de Feira de Santana, Bahia, assinalaram como negativos, principalmente, os aspectos que medem demanda psicológica, como "exigência de concentração" (71,6\%) e "ritmo acelerado de trabalho" (54,9\%), e os aspectos positivos mais referidos foram os relacionados com o controle, como "trabalho criativo" (100\%) e o suporte social, como "boa relação com os colegas" (93,7\%) 20.
Tabela 4

Freqüência dos diagnósticos médicos mais referidos por 233 professores da rede particular de ensino de Vitória da Conquista, Bahia, Brasil, 2001.

\begin{tabular}{lcc}
\hline Diagnóstico médico referido & $\begin{array}{c}\text { Freqüência } \\
\text { simples }\end{array}$ & $\begin{array}{c}\text { Freqüência } \\
\text { relativa (\%) }\end{array}$ \\
\hline Varizes em membros inferiores & 84 & 36,1 \\
Gastrite e esofagite & 56 & 24,0 \\
Infeção de trato urinário & 42 & 18,0 \\
Sinusite crônica & 41 & 17,6 \\
Lesões por esforços repetitivos & 41 & 17,6 \\
Calos nas cordas vocais & 31 & 13,3 \\
Anemia & 29 & 12,5 \\
Hipertensão arterial & 18 & 7,7 \\
Dermatite & 17 & 7,3 \\
Faringite crônica & 15 & 6,4 \\
Asma & 11 & 4,7 \\
Lombalgia & 9 & 3,9 \\
Outros & 25 & 10,7 \\
Nunca teve diagnóstico de problema de saúde & 62 & 26,6 \\
\hline
\end{tabular}

Merece especial atenção o fato de que uma população relativamente jovem ter referido em média, um número alto de problemas de saúde, dentre os trinta listados. As queixas de saúde mais freqüentemente referidas estavam relacionadas com a postura corporal, problemas psicossomáticos ou de saúde mental e queixas relacionadas à voz. Esse mesmo perfil de queixas foi detectado em outros estudos com professores 5,19,20,25,26,27.

O percentual de professores com diagnósticos médicos de saúde desde que começaram a trabalhar foi também elevado. É importante destacar que os diagnósticos mais freqüentemente referidos, em primeiro e quinto lugares, respectivamente, foram varizes em membros inferiores e lesões por esforços repetitivos, doenças potencialmente relacionadas ao trabalho.

Um terço dos professores referiu problemas de saúde nos 15 dias anteriores à entrevista, 0 que pode-se traduzir em elevado ausentismo ao trabalho. Esta porcentagem é semelhante à relatada para professores de Salvador 5 e em inquéritos domiciliares com populações de diversos países 28 .

A porcentagem de professores suspeitos de dependência do álcool foi reduzida e semelhante à relatada para professores de Salvador 4. O número de professores que se declararam fumantes também foi menor do que da média populacional brasileira, $23,9 \% 29$. 
Associação entre dor/formigamento nas pernas e permanecer em pé, segundo presença/ausência de varizes em professores da rede particular de ensino de Vitória da Conquista, Bahia, Brasil, 2001.

\begin{tabular}{|c|c|c|c|c|c|}
\hline \multirow[t]{2}{*}{ Varizes } & \multirow[t]{2}{*}{ Permanecer em pé } & \multicolumn{2}{|c|}{ Dor/formigamento nas pernas } & \multirow[t]{2}{*}{ Total } & \multirow[t]{2}{*}{ RP (IC95\%) } \\
\hline & & Freqüentemente & Raramente & & \\
\hline \multirow[t]{3}{*}{ Sim } & Freqüentemente & 50 & 29 & 79 & \\
\hline & Raramente & 2 & 1 & 3 & \\
\hline & Total & 52 & 30 & 82 & $0,95(0,42-2,15)$ \\
\hline \multirow[t]{3}{*}{ Não } & Freqüentemente & 57 & 81 & 138 & \\
\hline & Raramente & 1 & 2 & 3 & \\
\hline & Total & 58 & 83 & 141 & $1,24(0,25-6,22)$ \\
\hline \multirow[t]{4}{*}{ Total } & Freqüentemente & 107 & 110 & 217 & \\
\hline & Raramente & 3 & 3 & 6 & \\
\hline & Total & 110 & 113 & 223 & $0,99(0,44-2,22)$ \\
\hline & & & & & M.H.:1,05 $(0,48-2,29)$ \\
\hline
\end{tabular}

Destacou-se a alta prevalência de acidentes de trabalho referidos, se comparada àquela encontrada em professores de Salvador, 3,4\% 5 .

Apesar deste quadro ocupacional adverso, as escolas não realizavam exames médicos periódicos, mesmo estes sendo obrigatoriamente previstos na Norma Regulamentadora (NR-7) do Ministério do Trabalho 30.

A prevalência de distúrbios psíquicos menores observada neste estudo $(41,5 \%)$, superou amplamente os resultados relatados por outros autores, na faixa de 18 a $24,2 \% 4,16,18,19,20$. Cabe comentar que a pesquisa foi realizada num período de crise sindical e ao final do ano letivo, época de maior desgaste para os professores, como aponta Esteve 23. Travers \& Cooper 31 citam vários trabalhos sobre a dinâmica do estresse em professores durante o transcorrer do ano letivo. Um estudo canadense, referido por Travers \& Cooper 31, registrou maior incidência de estresse ao final de cada semestre e ao final do ano escolar. Ruiz et al. 32 registraram que as queixas de saúde e a procura por atendimento de saúde mostram forte tendência sazonal: são baixas no início do ano, elevam-se até o meio do ano, caem no início do semestre (após o período de férias) e voltam a subir significativamente no final do ano. Tendência similar pode ter ocorrido em Vitória da Conquista, pois os professores foram avaliados ao final do ano letivo. Deve-se ainda lembrar que os DPM costumam ser transitórios, o que contribui para superestimar a sua prevalência.

Entre as dez escolas avaliadas, a freqüência de DPM variou de $17,6 \%$ a $66,7 \%$, sugerindo que as condições de trabalho próprias de cada escola apresentam alguma influência nesta variação. Algumas características avaliadas pelo JCQ estavam fortemente associadas $(\mathrm{p}<0,05)$ com a prevalência de DPM, destacando-se as variáveis que representavam demanda psicológica e suporte social no trabalho. Apenas uma variável de controle sobre o trabalho apresentou associação com a prevalência de DPM. Trabalho repetitivo (indicador de controle) e ritmo acelerado de trabalho (indicador de demanda psicológica) também estavam estatisticamente associados com DPM em professores de Salvador 4.

Os estudos de corte transversal caracteristicamente apresentam dois tipos de limitações: só incluem aqueles indivíduos que "sobreviveram” à doença e, por coletarem simultaneamente dados de exposição e de doença, têm dificuldade para estabelecer uma relação de causalidade entre ambos. A maioria das doenças avaliadas na nossa pesquisa são crônicas, recorrentes, ou não letais, como varizes, lesões por esforços repetitivos e calos nas cordas vocais, pelo que dificilmente se perderam casos pelo primeiro tipo de viés. Mesmo assim, não podemos deixar de considerar as possibilidades de havermos perdido informação daqueles professores que: (1) abandonaram a profissão em decorrência de alguma doença ou desgaste relacionado ao trabalho; ou (2) por alguma razão, estavam ausentes do trabalho, na época da coleta de dados. Esteve 23 comenta que a época de maior ausentismo para os professores é ao final do ano escolar. Nesta última possibilidade, os nossos dados estariam subestimando a real prevalência da morbidade. 
O tipo de amostragem de conveniência utilizado, que selecionou as dez maiores escolas de Vitória da Conquista, pode ter comprometido a representatividade. Esta limitação decorreu da inexistência de um cadastro fidedigno de todas as escolas particulares da cidade. As condições de trabalho nas escolas particulares maiores são provavelmente diferentes das menores, envolvendo ambientes menos familiares e com maior número de alunos.

Da listagem inicial de professores, conseguiu-se uma proporção de resposta de 80,9\%, considerada na classificação de Babbie 33 como "muito boa". Um inconveniente dos questionários auto-aplicativos é a opção do entrevistado não responder a todas as perguntas, sendo difícil de controlar, pela mesma condição de anonimato da pesquisa.

\section{Resumo}

A literatura científica sobre a saúde dos professores é escassa e recente, enfocando especialmente o desgaste e estresse. Este trabalho objetivou descrever as condições de trabalho e saúde dos professores da rede particular de ensino da cidade de Vitória da Conquista, Bahia, Brasil. Num questionário auto-aplicado foram coletadas informações de 250 professores de dez escolas. Entre as características do trabalho docente, avaliadas pelo Job Content Questionnaire, destacaram-se ritmo acelerado de trabalho, ser criativo e ter boas relações com as pessoas no trabalho. As queixas de saúde mais freqüentes estavam relacionadas à postura corporal, à saúde mental e a queixas relacionadas à voz. A prevalência de distúrbios psíquicos menores (DPM), medida pelo Self Reporting Questionnaire-20, foi de 41,5\% e estava fortemente associada a longos períodos de intensa concentração em uma mesma tarefa e volume excessivo de trabalho. Os resultados sugerem relação entre a prevalência de DPM e algumas características do trabalho docente, evidenciando desgaste psicológico do educador.

Condições de Trabalho; Saúde Ocupacional; Docentes

\section{Colaboradores}

N. S. Delcor, T. M. Araújo e E. J. F. B. Reis participaram da concepção e desenho do estudo; N. S. Delcor, T. M. Araújo, E. J. F. B. Reis, M. O. Silva, L. Barbalho e J. M. Andrade realizaram a coleta de dados; todos os autores participaram da análise e interpretação dos dados; a elaboração da versão inicial do manuscrito foi feita por N. S. Delcor; todos os autores revisaram o manuscrito e aprovaram sua versão final, submetida à publicação; pequenas alterações no texto foram realizadas por F. M. Carvalho, T. M. Araújo e L. A. Porto, em resposta às análises dos revisores.
Em conclusão, encontrou-se uma população de professores jovens e de sexo feminino, com elevada carga horária, vários locais de trabalho, baixa renda mensal e alta demanda psicológica e física. Este grupo ocupacional apresentou elevada proporção de queixas e diagnósticos de problemas de saúde. Destacou-se a elevada prevalência de professores com distúrbios psíquicos menores $(41,5 \%)$ que supera resultados relatados em outros estudos. Constatou-se associação entre a prevalência de distúrbios psíquicos menores e algumas questões do JCQ, principalmente aquelas relacionadas à demanda psicológica e ao suporte social. Os resultados apóiam a hipótese de que o desgaste do corpo dos professores é determinado, em boa parte, pelo tipo e pela forma de organização de seu trabalho.

\section{Referências}

1. Dejours C. A loucura do trabalho: estudo de psicopatologia do trabalho. São Paulo: Editora Cortez/Oboré; 1987.

2. Codo W, Vasques I. Trabalho docente e sofrimento: burnout em professores. In: Azevedo J, Gentili P, Krug A, Simon C, organizadores. Utopia e democracia na educação cidadã. Porto Alegre: Editora Universidade; 2000. p. 369-81.

3. Codo W. Educação: carinho e trabalho. Petrópolis: Editora Vozes; 1999.

4. Araújo T, Silvany A, Reis E, Kavalkievicz C. Condições de trabalho e saúde dos professores da rede particular de ensino: Salvador-Bahia. Salvador: Sindicato dos Professores do Estado da Bahia; 1998.

5. Silvany AM, Araújo T, Dutra F, Azi G, Alves R, Kavalkievicz C, et al. Condições de trabalho e saúde de professores da rede particular de ensino de Salvador, Bahia. Rev Baiana Saúde Pública 2000; 24:42-6.

6. Instituto Nacional de Estudos e Pesquisas Educacionais. Censo do professor, 1997: perfil dos docentes de educação básica. Brasília: Instituto Nacional de Estudos e Pesquisas Educacionais, Ministério de Educação e Cultura; 1999.

7. Karasek RA. Job content questionnaire and user's guide. Revision 1.1. Lowell: University of Massachusetts; 1985.

8. Karasek R, Theorell T. Healthy work: stress, productivity, and the reconstruction of working life. New York: Basic Books; 1990.

9. Karasek RA, Brisson C, Kawakami N, Houtman I, Bongers P, Amick B. The Job Content Questionnaire (JCQ): an instrument for internationally comparative assessments of psychosocial job characteristics. J Occup Health Psychol 1998; 3: 322-55.

10. Pelfrene E, Vlrick P, Mak RP, Smets P, Kornitzer M, Backer G. Scale reliability and validity of Karasek 
'Job Demand Support' model in the Belstress study. Work Stress 2001; 15:297-313.

11. Araújo TM. Modelo demanda-controle (Job strain model): proposições, limites e usos em estudos de estresse e saúde ocupacional. In: Anais do VI Congresso Brasileiro de Saúde Coletiva [CD-ROM]. Rio de Janeiro: ABRASCO; 2000.

12. Harding TW, Arango MV, Baltazar J, Climent CE, Ibrahim HHA, Ladrido-Ignacio L, et al. Mental disorders in primary health care: a study of their frequency and diagnosis in four developing countries. Psychol Med 1980; 10:231-41.

13. Mari JJ. A validity study of a Psychiatric Screening Questionnaire (SRQ-20) in primary care in the city of São Paulo. Br J Psychiatry 1986; 148:23-6.

14. Fernandes SRP, Almeida Filho N. Validação do SRQ em amostra de trabalhadores em informática. Revista Brasileira de Saúde Ocupacional 1998; 89:105-12.

15. Masur J, Monteiro MG. Validation of the "CAGE alcoholism screening test in a Brazilian psychiatric inpatient hospital setting. Revista Brasileira de Medicina e Pesquisas Biológicas 1983; 16:215-8.

16. Cifuentes M. Sintomatología psiquiátrica según SRQ-20 y factores asociados en profesores municipalizados de la comuna de Talcahuano [Tese de Doutorado]. Concepción: Facultad de Medicina, Universidad de Concepción; 2000.

17. Organização Internacional do Trabalho. Servicios de educación y formación. In: Enciclopedia de salud y seguridad en el trabajo. http://www.mtas. es/insht/EncOIT/Index.htm (acessado em 04/ Out/2002).

18. Oliveira MG. Condições de trabalho, gênero e saúde: sofrimento e estresse. Um estudo de caso com os profissionais docentes do ensino superior privado de Belo Horizonte [Dissertação de Mestrado]. Belo Horizonte: Pontifícia Universidade Católica de Minas Gerais; 2001.

19. Wernick R. Condições de saúde e trabalho dos docentes da Universidade Federal da Bahia, Salvador - BA [Dissertação de Mestrado]. Salvador: Instituto de Saúde Coletiva, Universidade Federal da Bahia; 2000.

20. Paranhos I. Interface entre Trabalho Docente e Saúde, dos Professores da Universidade Estadual de Feira de Santana [Dissertação de Mestrado]. Feira de Santana: Departamento de Saúde, Universidade Estadual de Feira de Santana; 2001.
21. Ministério do Trabalho. Relatório anual de informações sociais (RAIS). Brasília: Ministério do Trabalho; 1995

22. Gomes L. Trabalho multifacetado de professores/ as: a saúde entre limites [Dissertação de Mestrado]. Rio de Janeiro: Escola Nacional de Saúde Pública, Fundação Oswaldo Cruz; 2002.

23. Esteve JM. O mal-estar docente: a sala de aula e a saúde dos professores. São Paulo: Edusc; 1999.

24. Lan Osasuna. Encuesta Navarra salud y condiciones de trabalho 1997. http://www.stee-eilas. org (acessado em 24/Out/2002).

25. Centro de Estudos e Saúde do Trabalhador. Análise de demanda do ambulatório. Salvador: Centro de Estudos e Saúde do Trabalhador; 1997.

26. Smith E, Gray SD, Dove H, Kirchner L, Heras H. Frequency and effects of teachers' voice problems. JVoice 1997; 11:81-7.

27. Penteado R, Pereira IM. A voz do professor: relações entre trabalho, saúde e qualidade de vida. Revista Brasileira de Saúde Ocupacional 1998; 95/96:109-30

28. Carvalho FM, Silvany AM, Paim JS, Melo AMC, Ázaro MGA. Morbidade referida e utilização de consulta médica em cinco populações do Estado da Bahia. Ciênc Cult 1988; 40:853-8.

29. Fundação Nacional de Saúde. Pesquisa nacional sobre saúde e nutrição. http://www.funasa.gov. br/pub/GVE/GVE0535B.htm (acessado em 9/ Out/2002).

30. Ministério do Trabalho. Portaria federal no 3.214, de 8 de junho de 1978. Diário Oficial da República Federativa do Brasil 1978; 6 jul.

31. Travers CJ, Cooper CL. Fuentes del estrés en la enseñanza. In: organizador. El estrés de los profesores. La presión en la actividad docente. Barcelona: Editora Paidos; 1997. p. 57-101. (Temas de educación).

32. Ruiz RC, Seixas AAA, Heck B, Prio EL, Ruiz V. Risco dos mestres. Revista Proteção 1998; 76:45-8.

33. Babbie ER. Questionários auto-aplicativos. In: Babbie ER, organizador. Métodos de pesquisas de Survey. Belo Horizonte: Editora UFMG; 1999. p. 247-58.

Recebido em 14/Jan/2003

Versão final reapresentada em 26/Jun/2003

Aprovado em 16/Out/2003 